\title{
HUMANITARIAN LOGISTICS: REVIEW AND CASE STUDY OF ZIMBABWEAN EXPERIENCES
}

\author{
CHARLES MBOHWA \\ cmbohwa@uj.ac.za \\ Department of Quality and Operations Management \\ University of Johannesburg \\ South Africa
}

\begin{abstract}
This paper reviews and presents findings on mini-case studies done on the difficulties and problems faced by humanitarian organisations in running logistics systems in Zimbabwe. Document analysis was done and this was complemented by mini-case studies and semi-structured interviews and site visits. Mini-case studies of the operations of the World Food Programme, the International Red Cross Society and the Zimbabwe Red Cross Society, the World Health Organisation, the United Nations Children's Fund and the Zimbabwean Civil Protection Organisation in Zimbabwe are discussed. These clarify the difficulties and problems faced such as the lack of trained logistics personnel, lack of access to specialised humanitarian logistics courses and research information, the difficulty in using and adapting existing logistics systems in attending to humanitarian logistics and the lack of collaborative efforts that address the area specifically. This study seeks to use primary and secondary information to inform decision-making in humanitarian logistics with possible lessons for neighbouring countries, other regions in Africa and beyond. Activities on collaborative networks that are beneficial to humanitarian logistics are also suggested.
\end{abstract}

\section{INTRODUCTION}

When humanitarian disasters occur, organisations respond by delivering aid to people in need. Their supply chains need to be both fast and agile, responding to sudden-onset disasters, which may occur in cities or in far places like rural areas in a developing country. Since 2004, many large-scale natural disasters and humanitarian emergencies have captured the attention of the international media. Situations of humanitarian emergencies are defined as a situations in which at least 300000 people can die if there is no international assistance (Miskel, 2000). Examples are the 2004 Indian Ocean tsunami, Hurricane Katrina in 2005 that devastated New Orleans, the 2005 earthquake in South Asia, and most recently the earthquake in Haiti in 2010. Disasters of this magnitude cause donors, beneficiaries, and the media to closely monitor how quickly and efficiently humanitarian organisations are able to respond. 
Operations can be required in many challenging places, causing the corporate sector and businesses to back off, because there is no business case and the costs are tremendous. Creating and implementing complicated logistics solutions and dealing with the last leg between the final distribution centre and the beneficiary or client is a challenge, and can also be very costly. Humanitarian logistics seeks to address these issues. It involves organisational components such as procurement, transportation, warehousing, inventory management, tracking and tracing, bidding and reverse bidding, reporting and accountability to address emergency needs. The humanitarian environment is becoming increasingly complex, requiring a deeper understanding of conflict, security and local and international politics. There is a school of thought that intervention should be done before a crisis reaches boiling point to reduce the impact or extent of humanitarian disasters. It has also been noted that when an emergency develops aid can reduce local prices of food and create a never-ending cycle of continuous dependency and risk to the local society (Miskel, 2000).

Humanitarian organisations also tend to be highly dependent on grants, which are generally geared towards paying for direct project and programme inputs in the field. Projects and programmes are time-bound, often under-funded. The practitioners in this field live from grant to grant and project to project and this does not allow for a healthy strategic process to develop as both planning cycles and funding cycles are generally unpredictable. This discourages investment in improved information systems. These issues justify a need to consider humanitarian logistics as a special field on its own that requires attention. This paper addresses some of the problems and challenges faced by humanitarian logistics organisations in Zimbabwe. It suggests systems that can be used to improve humanitarian logistics in those organisations or in similar operations in other countries.

\section{LITERATURE REVIEW}

Humanitarian emergency logistics normally focuses on the response phase of disaster management aimed at search and rescue, sustaining or saving life, and restoring self-sufficiency. These operations are impeded by the resulting logistical problems, difficulties in organising emergency response (which affects decision-making and coordination), disaster-management policy (mitigation, prevention and preparedness), the social and economic environment of the area affected by the disaster, an over-abundance of financial resources (proliferation of responding actors, marginalisation of local actors by international actors and assistance without a needs assessment) and poor coordination (Thevenaz \& Resodihardjo, 2010).

A disaster-response operation involves trade-offs of speed, cost and accuracy with regard to the type of goods that are delivered and their quantities. The difficulty of moving staff in large numbers to the field and ensuring their safety and shelter during humanitarian crises has increasingly become a topical issue. Complex humanitarian emergencies resulting from 
conflict at many different levels have had serious impacts on health, economics and social stability and are mostly based on a struggle for power, wealth and authority. Terrorism of international and national humanitarian relief workers has become rife (Lautze, Leaning, Raven-Roberts, Kent \& Mazurana, 2004). The safety of relief sites and personnel is no longer assured as murders of relief and international aid agency workers have occurred. In some cases the cost of providing security to aid workers and relief operations is up to five times the cost of the relief supplies and operations as was the case in Somalia in 1991 (Miskel, 2000). This cost adds to the conventional costs of humanitarian logistics and operations. Logistics costs have been found to be about $80 \%$ to $90 \%$ of the total expenditure of a humanitarian organisation. There is also the realisation that education and training can provide improvements to the effectiveness and efficiency of logistics support, which is helping to reduce costs in the process (Gyongyi \& Tatham, 2009).

As described by the United Nations Joint Logistics Centre (UNJLC), humanitarian logistics during emergencies requires:

- delivery of the appropriate supplies in good condition, when and where they are needed

- a wide range of transport, often improvised at the local level

- limited, rapid, and specific deliveries from outside the area affected

- a system of prioritising various relief inputs

- storing, staging, and moving bulk commodities

- moving people

- coordination and prioritisation of the use of limited and shared transport assets

- possible military involvement in logistics support (especially in cases of civil conflict).

The main factors in the operating environment which shape the response to humanitarian crises are:

- capacity of the infrastructure

- availability and quantity of transport assets in the country

- politics of the situation

- civil conflict in the area of operations (UNJLC, 2008).

The structure and organisation of humanitarian logistics is based on the nature of the supply chain in question. Components of this chain comprise 1) port of entry; 2) primary warehouse; 3) forward warehouse; and 4) terminal storage point. A typical humanitarian logistics structure starts at the points of origin, for example producing or donor countries, to one or more ports of entry, which can be land, sea or airports, and one or more primary warehouses (near the port of entry), through to forward warehouses (for holding), and lastly to terminal storage points from which the relief goods are transferred to places of distribution to the beneficiaries (UNJLC, 2008). The humanitarian logistics and relief chain structure includes pre-disaster procurement, stock pre-positioning, post-disaster procurement and transportation. Consideration must be given to the main issues in the humanitarian logistics operations, which are: 
- Local procurement is quick, but can cause price increases. International procurement is slower and can also cause destructive price reductions. In-kind donations can also cause chaos and congestion.

- Pre-positioning stock quickens responsiveness but is costly in terms of inventory costs.

- Transportation for the last mile has been reported to be difficult, due to limited transportation resources, damaged infrastructure and the large volumes that can be required.

- Coordination can exist between relief agencies mainly in joint decisions, common information systems and resource sharing. Coordination relationships between relief agencies, local/military and international agencies and between agencies and private sectors have been studied. Some of the methods for supply chain coordination are procurement coordination, warehousing/inventory coordination, transportation coordination and 3PL or 4PL coordination (Balcik, Beamon, Krejci, Muramatsu \& Ramirez, 2010).

Supply chain professionals in the commercial sector face many of the same issues of tradeoffs in performance as a professional working in humanitarian logistics operations. In business and in humanitarian disaster relief, supply chain speed is of the essence. These similarities suggest that it is important to understand the underlying principles of commercial and humanitarian logistics operations performance measurement systems when developing a system for humanitarian disaster relief operations. The following principles are critical:

- aligning metrics to the organisation's core strategy to avoid cluttered indices (Lambert, 2001)

- understanding the dynamics of how performance is driven by knowing and tracking key success factors (Caplice \& Sheffi, 1994).

Prior disaster awareness and readiness, accurate and specific early warning, effective prioritisation, plans and planning, unity of direction and whole of government response, and the launching of immediate operations to assist affected populations by the army when necessary are key factors (Oloruntoba, 2010). Metrics should be periodically reviewed as performance improves (Meyer, 2005).

In addition, humanitarian logisticians use more indicators that may not necessarily apply to commercial and military logistics operations, for instance (Caplice and Sheffi, 1994):

- Appeal coverage comprising two specific metrics:

○ \% of appeal coverage; and

○ \% of items delivered. The first metric is the quantity of items that have been pledged by donors out of the total number of items requested for the operation. The second metric is the percentage of items that have actually been delivered on-site out of the total number of items requested for the operation.

- Donation-to-delivery time measures how long it takes for an item to be delivered to the destination country after a donor pledge.

- Financial efficiency is made up of three relative and absolute financial efficiency metrics to compare the budgeted prices to the actual prices paid for items delivered, and a 
financial efficiency metric that incorporates the transportation cost of delivering the goods to the beneficiaries expressed as a ratio of the total transportation costs incurred to the total costs for delivered items at a point in time.

- Assessment accuracy measures how quickly donations are pledged and delivered to beneficiaries.

Humanitarian logistics also encompasses the relocation of disaster-affected people, transfer of casualties, and the movement of relief workers. Supply chains must therefore be both fast and agile (Caplice \& Steffi, 1994). As mentioned any disaster-response operation involves trade-offs of speed, cost, and accuracy with regard to the type of goods that are delivered and their quantities. Balancing these trade-offs requires a means of measuring supply chain performance. However, the inability to centrally capture time and cost data related to the procurement and distribution of goods has prevented a systematic process of performance measurement from being implemented (Dumond, 2000).

\section{METHODOLOGY}

In this study, document analysis was done and this was complemented by mini-case studies and semi-structured interviews and site visits. This methodology was chosen because analysis of documents produces incomplete information. Documents only capture information from the viewpoint of the designer and producer of the documents. The method for collecting the data was in the form of narrative research inquiry directing to case study approach and analysis. This method or technique was realised by semi-structured interviews with management and personnel in the organisations studied, through analysis of existing documents, Internet searches and visits to the main offices of the organisations and some of the depots around the country. Data collected sought to understand the problems and challenges faced by the humanitarian organisations in their logistics operations. As indicated, data were also collected from secondary sources, that is, data from other researchers, from literature and from electronic sources.

For all the cases, general information on the details of the humanitarian logistics operations was collected. This served to introduce the organisation in detail and to identify the problems and challenges faced by the organisation with a specific focus on operations in Zimbabwe. That way an analysis could be done to assess the similarities and dissimilarities of the different case studies. General reflection and comparison of the case studies was also done with a view to identifying and classifying the challenges and problems faced by the organisations. Solutions and recommendations were then identified in order to attend to the identified deficiencies, problems and challenges. 


\section{HUMANITARIAN LOGISTICS AT THE WORLD FOOD PROGRAMME IN ZIMBABWE}

Humanitarian logistics is very important for the World Food Programme (WFP) because lives depend on it. It is one of the world's largest humanitarian aid organisations and the United Nations' largest frontline relief agency.

\section{General WFP operations worldwide and in Zimbabwe}

WFP logistics has over 2000 employees worldwide and its supply chain begins by procuring privately or by receiving aid from government and donors. The cargo is shipped using trucks, helicopters, scotch carts and even animals such as elephants and donkeys among many other modes. At times it carries out special operations when necessary to improve local transport infrastructure, including rebuilding of roads, bridges and railways, de-mining and rehabilitating ports. The problems faced by WFP operations in Zimbabwe have been found to be similar to those confronted in other African countries. Even though Zimbabwe has had a food deficit for the last 20 years due to poor government policies, it has in addition several characteristics which constrain the delivery of food relief. The staple food is made from maize meal and other grains like millet. Distances to be covered during logistics operations are long, roads and railways are of poor quality and of insufficient length to reach the desired areas. This has been worsened by the deteriorating economy resulting in failure to maintain and expand logistics infrastructure. In order to ensure effective delivery, the WFP made special provisions to pay for up to half the cost of internal transport, storage and handling of food aid (WFP in Africa, 1984). Despite such commitments the government in Zimbabwe has found it difficult to meet the remainder of the costs, bringing the financial burden back to the WFP. The food-deficient areas were also found to be unstable due to the political interference and culture of violence developed by the ruling party. This also posed great risks to the WFP logistics staff. However strategies have been developed to deal with such situations within the WFP system, based on experiences in Afghanistan (WFP, 1994).

One of the biggest challenges that the WFP has continued to face is overcoming the time lag between disasters occurring and donations coming in (WFP, 2005). In some cases food resources arrived in Zimbabwe very late after passing through checks and controls in neighbouring countries. The UN logistics service has a fleet of trucks to transport relief commodities to designated delivery points (Gustavsson, 2006). A number of these trucks has been placed in Zimbabwe. It has also subcontracted some trucks from the private sector. Trucks, mostly those contracted, have been workhorses of the WFP logistics in Zimbabwe and carried most of the loads. WPF relies largely on contracted road transport for most of its deliveries. However in some cases they use owned fleets. Trucks have also been used 
for distribution from one locality to the other. Poor roads in Zimbabwe were found to be a major problem such that the WFP ended up taking part in repairing damaged roads. In some instances the WFP went to the extent of reopening roads previously closed due to physical deterioration in an effort to reduce transportation cost (WFP, 1995).

The WFP storage depots are distributed all over the world and are mainly located at ports. The Southern African WFP has four depots located in Mozambique from which most of the supplies to Zimbabwe are made. The operations involve assuming responsibility for port depot inventory and storage management. Storage management also entails activities such as insect pest management. Fumigation activities are carried out in order to reduce grain deterioration. The logistics teams are also responsible for monitoring stock levels and replenishing stocks. WPF through its logistical team establishes the need areas and the level of food requirements through relevant ministries of the government of Zimbabwe as the starting point (WFP, 1986). Once all stakeholders agree on the validity of the needy area and specific requirements for the area, the WFP logistics team takes over the responsibility of distribution and monitoring. In some instances the WPF logistics team received assistance from the relevant government departments and ministries. However this resulted in clashes between the two parties as differences arose on the issue of the politicisation of food distribution in order to 'buy' votes. Clashes also arose due to the different perceptions of problem identification, monitoring and distribution methods between the political parties.

The monitoring phase involves logistics personnel conducting registration verification through visits to households. Monitoring is done at distribution sites and encompasses postdistribution monitoring as well. This enables evaluation and assessment of the extent to which relief distribution objectives are met. It also ensures the smooth flow of the distribution process and equitable distribution of relief. The WPF logistics team also employs a specific monitoring check for each specific programme. They also monitor and report monthly any political incidents surrounding the programme activities (WFP, 2005). In order to improve its targeting of assistance to needy groups, WFP carries out Vulnerability Analysis and Mapping for pinpointing food needs. The WFP operations in Zimbabwe are part of a global and regional logistics network. They address natural disasters due to poor harvests, drought and cyclones and man-made disasters caused by the political and economic upheaval since the year 2000 in Zimbabwe (WFP Zimbabwe, 2006). The following aspects usually provide the guidelines for the decisions that are made to provide relief aid in Zimbabwe:

- Commercial setup: Are the areas in need of aid accessible by road and how far are they from these commercial centres?

- Are there any warehouses and if so what is the storage capacity? (If they are large enough the WFP leases them.)

- Are any temporary storage facilities required or should new warehouses be built? (If there is need the WFP erects temporary warehouses.) 
- Are there any non-governmental organisations (NGOs) currently in place and to what extent are they meeting the demand? (WFP, 2005)

\section{Problems and challenges faced by WFP Zimbabwe}

Distribution of food aid (maize, maize meal, peanuts and cooking oil) in Zimbabwe is affected by a number of factors that include the nature of existing roads, dust roads or gravel roads and their condition. The road condition varies seasonally and yearly especially after the rainy season. The strength or lack of bridges is another issue of concern, and the Local and Central Government setup also affects food distribution. Logistics operations are dynamic and subject to political interference. In Zimbabwe, before food donations are distributed, the government inspects the food to ensure that it is not genetically modified (GM) and a GM certificate is issued before the donations are shipped into the country in the form of grains. Otherwise the grains have to be milled before they enter the country. The location of the central hubs where the bulk of the food aid is to be stored changes depending on source, port of entry and the regions where food aid is urgently needed. Removal of stored food is normally scheduled on a First In First Out (FIFO) or First to Expire First Out (FEFO) basis. At the final destination zones, WFP leases sub-warehouses and/or erects mobile storage for distribution at various places like schools, hospitals and other points of need (WFP, 2005).

The WFP logistics programme in Zimbabwe faces several problems and challenges, as follows:

- The free-fall of the economy has resulted in a shrinking supply base due to the drop in local production and the weaker currency. The exchange rate fell drastically and the zeros in the currency were reduced in sixes twice. The currency has since stabilised and a basket of currency is used including mainly the UStates dollar, the South African rand and the British pound. This has made it easier for the WFP to plan.

- Infrastructure in the country has deteriorated due to the economic and political problems. The roads have not been adequately maintained and fuel shortages were prevalent between year 2000 and early 2009.

- Storage and distribution facilities were at times looted and the whole exercise politicised by the ruling party, rendering some of the humanitarian operations ineffective. Additionally distribution of food aid has been frequently affected by politics. Directives from the government to release particular commodities to a particular location negatively affected the planned delivery schedules and resulted in the expiry of certain foods. Threats and violence hampered delivery to needy opposition party members and the delays in issuing GM certificates through lengthy bureaucratic procedures also delayed delivery impacting negatively on WFP operations (WFP, 2005).

- Some of the donations received in kind were not in synch with what is required at a given moment. For example there were donations of rice and non-staple child food instead of 
the required maize grains/meal. In some cases donations were inadequate resulting in food rationing (WFP, 2005).

- Some operations were hampered by lack of information and communication technology. Documentation relating to transportation often produced electronically at the point of origin was often only available on-line at the point of use due to a lack of electronic infrastructure by partner organisations. This resulted in delays, increased the time required to handle information and led to reduced efficiencies, duplication of functions, increased inaccuracies in reporting and increased costs (WFP, 2005).

- The existing logistics structure at WFP Zimbabwe was found to be loose and in some parts extremely multi-organisational. This was based on historical responses to different emergency situations and resulted in the loss of commodities and slow reaction to new and developing needs. Diversions of relief aid occurred especially at the delivery points where informal systems existed due to lack of infrastructure and systems (WFP, 2005).

- The people in charge of humanitarian logistics at WFP and its partners were found to have no formal training in logistics. Many employees began their careers with a background in the social sciences, development studies or law. Few had corporate experience of logistics management. Some of the key logistics support mechanisms were found to be lacking in the WFP in Zimbabwe, even though they are available in the private sector and the military. Examples are expert staffing, know-how, information technology (IT) systems, management information systems (MIS), framework agreements, corporate relationships, infrastructure, standardisation and collaborative initiatives.

\section{HUMANITARIAN LOGISTICS AT ZIMBABWE RED CROSS SOCIETY}

The International Federation of the Red Cross and Red Crescent Societies (IFRC) is regarded as being the world's largest humanitarian organisation, with 186 member national societies. The organisation is guided by the seven fundamental principles of humanity, impartiality, neutrality, independence, voluntary service, unity and universality (IFRC, 2010).

\section{General Red Cross Society operations worldwide and in Zimbabwe}

IFRC is mainly involved in humanitarian disaster management, capacity-building and health issues. The organisation operates in many countries and attends to any hot spots. Recent areas of focus have been the floods in Pakistan and in North Korea, the Belarus campaign for preparedness and response against all strains of influenza, the earthquake in Haiti, tsunami operations and finding ways to beat malaria in affected areas in Africa and all over the world (IFRC, 2010). Zimbabwe is one of the partner countries with a national society affiliated to IFRC, the Zimbabwe Red Cross Society (ZRCS). It was established in 1932 as a branch of the British Red Cross until 1981 when it began to be recognised in Zimbabwe through an Act of Parliament. In 1983 it was recognised by the International Community of the Red Crescent Society (ICRC) (Mazvimavi, 2000). The Society is supported by a regional 
international federation delegation whose aim is to coordinate and deliver programmes and initiatives, most of which are funded by Red Cross donors either bilaterally or through federation appeal. It also assists the Society to develop and expand links with all stakeholders including local and international media, diplomatic missions, civil society representatives, local authorities, NGOs and the corporate sector to secure coverage and funds for some of its humanitarian activities (IFRC, 2002).

The ZRCS operates countrywide under a similar administrative structure to the local government. Beneath the National Executive Council (NEC) are eight provincial committees, then 57 district committees. At present, there are 282 branches. The district offices usually deal with issues of food distribution and community support while the provincial offices are there to provide support to their respective districts. The provincial offices arrange temporary warehousing of goods before they are distributed and are responsible for organising the transportation of goods. The NEC is involved in issues of a strategic nature involving planning, advocacy and the sourcing and movement of goods and services from local and international donors. Trained volunteers, usually members, from same community in which the support is offered, provide services and support on behalf of the Society. They are given small allowances for food and transport. ZRCS has approximately 20000 adult members/volunteers and 19000 youth members/volunteers (IFRC, 2007).

ZRCS has been implementing projects in the health sector since 1988 and key programme elements within this sector include:

- The integrated HIV/AIDS programmes involving information dissemination on HIV/ AIDS prevention and home-based care for people living with HIV/AIDS through training and counselling as well as provision of clothes, nutritional support and distribution of drugs such as antiretrovirals (ARVs). Their support for orphans and vulnerable children by providing basic needs is complemented by the Danish and Japanese Red Cross Societies.

- The United Nations Children's Fund (UNICEF) also provides complementary support to this programme and has collaborative systems in community-based first-aid training to action teams and other members of the community; and water and sanitation programmes which involve the rehabilitation of boreholes/wells, building of new latrines in affected areas as well as providing water purification tablets to improve water quality.

- ZRCS provides funding for disaster management programmes placing much emphasis on preparedness measures both in communities and within the Society itself to enable a quick and better response when humanitarian disasters like drought and floods occur, through capacity development at community level and supporting branch and youth development.

- Other activities include complementary food-for-work programmes and provision of shelter (tents) and clothes. Integrated food security programmes are supported, 
reinforcing self-reliance and coping mechanisms with a vision of enabling self-sustenance of communities and households. This is done through the provision of agricultural inputs (IFRC, 2007).

Needs assessments are normally carried out by the Vulnerable Assessment Committees consisting of government authorities, UN agencies and the International Federation of the Red Cross. It has been realised that the food security programmes are most effective when built around or with the ongoing HIV and AIDS mitigation activities since there are already existing beneficiary systems in place.

\section{Problems and challenges faced by the ZRCS}

The Society faces several problems and challenges in both its operational programmes and logistical operations as follows:

- The rapid increase of beneficiaries in the communities has resulted in increased pressure on the Society. Extra funds need to be sourced to cater for the growth and these are sometimes unavailable.

- There is an increase of HIV/AIDS cases stretching the limited resources.

- Lack of safe drinking water in many rural areas is causing health problems.

- Reaching out to beneficiaries located in remote locations particularly where roads are non-existent is extremely difficult.

- The Society also faces limitations in retaining skilled staff due to the low wages offered and this has had a major impact on its activities.

- The Society is also not spared political harassment by some local members of the society particularly since its corporate colours are similar to those of the main opposition political party (Mazvimavi, 2000).

\section{HUMANITARIAN LOGISTICS AT THE WORLD HEALTH ORGANISATION ZIMBABWE}

The idea to set up the World Health Organisation (WHO) was discussed by the diplomats who met to form the United Nations in 1945. Its constitution came into force on 7 April 1948. It directs and coordinates health issues and activities within the United Nations system. It takes a leading role on global health matters locally and globally and shapes a health research agenda that can inform evidence-based policy options. It provides technical support for the 193 member countries (WHO, 2010) and monitors and assesses health trends. This enables collective defence against trans-national health threats (WHO, 2010). Humanitarian logistics operations play a vital role within this mandate.

\section{General WHO operations worldwide and in Zimbabwe}

It has become more evident in the new millennium that health is a shared responsibility. There is therefore need for equitable access to essential health care and collective defence 
against transnational health threats like the evolving strains of influenza. The health statistics are not encouraging and point to a need for more effective global efforts. The reality is that more than 1.8 million people between the ages of 15 and 24 years die each year from mostly preventable diseases. Around 16 million girls aged 15 to 19 years give birth and $40 \%$ of new HIV infections are accounted for by young people between 15 and 24 years old. These statistics point to a need for effective humanitarian logistics systems that can ensure global medicine access to tackle preventable diseases, global dissemination of family planning kits and information, and dissemination of effective HIV/AIDS prevention and combating systems worldwide.

Recent worldwide WHO operations have focused on addressing the health needs of the increasingly ageing societies; prevention of child maltreatment, homicides and suicides; and tuberculosis and HIV/AIDS prevention in Africa and other waste-affected countries. Effort is being made to improve health systems in member countries and in international travel and related health issues to combat dangerous flu strains and communicable diseases. WHO provides updates of information on disease outbreaks and how to contain them. Attention is paid to humanitarian emergencies and disasters worldwide. There are activities to ensure rational use of medicine and polio eradication, and equitable distribution of and access to medicines covering all areas of health and diseases worldwide. In all there are more than 200 projects running at any time (WHO, 2010).

The WHO is facing several logistics challenges in its endeavour to provide health services worldwide, especially in Africa and Asia. In most African countries unplanned disease outbreaks such as malaria, cholera, dysentery, measles and pneumonia pose a serious challenge to the general preparedness of WHO. Outbreaks of war and the rainy season have posed greater challenges especially in African countries such as Sudan and its Darfur region. Zimbabwe faces similar problems. Every year at the onset of the rains, malaria outbreaks occur. Recently cholera, dysentery, measles and pneumonia have been prevalent countrywide and these diseases have stressed the increasingly fragile health delivery system.

\section{Problems and challenges faced by WHO in Zimbabwe}

The serious logistical problems and challenges facing WHO in Zimbabwe include:

- Hospital service quality in the country has become very poor. Most of the hospitals, including the country's referral centres, are inadequately equipped to cater for epidemics.

- Access to health services by people in dire need is very poor due to the deteriorating transportation infrastructure and lack of affordability. Doctors' consultations, hospital beds, medication and consumables have become very expensive for the ordinary people. 
- The lack of coordination among agencies due to poor communication networks in the country has limited the effectiveness of the organisation in its effort to ensure basic health services to the population.

- There is limited access to primary health care.

- The exodus of medical professionals to other countries has created a serious manpower shortage.

- Reports of abuse of drugs, looting, violence and killing for political reasons have become common problems further stretching the health services.

- Prompt provision of basic food, water and health services to thousands of villagers spread across long distances along non-maintained roads has become a formidable task.

- Government support of the health delivery systems is lukewarm.

- The health situation has been worsened by the low and fast shrinking GDP in Zimbabwe. WHO can only offer limited help and a dysfunctional system is not a good environment for that. As a result a cholera outbreak killed more than 4000 people in 2009. However the economic decline has been arrested since February 2009, when a loose coalition government was formed.

- The number of NGOs effectively participating in the health sector has declined due to delays on travel permits and cumbersome clearance of goods or vehicles.

\section{HUMANITARIAN LOGISTICS AT UNICEF ZIMBABWE}

UNICEF is an integral member organisation of the United Nations (UN) and is mandated by the United Nations General Assembly to advocate for the protection of children's rights, to help meet their basic needs and expand their opportunities to reach their full potential. It seeks to mobilise political will and material resources to help countries to ensure that the welfare of children receives top priority. The organisation also assists in building the capacity of the countries in which it operates to form appropriate policies and deliver services for children and their families. It responds during emergencies to protect the rights of children in coordination with other humanitarian partners. UNICEF also makes unique facilities for rapid response available to its partners to relieve the suffering of children and for those who provide their care (UNICEF, 2008).

\section{General UNICEF operations worldwide and in Zimbabwe}

Aid from donor countries is transported normally by ship to the ports closest to the target country - Beira and Durban in the case of Zimbabwe and other Southern African countries. Important areas of focus are the state of the infrastructure such as roads, security, legislative issues and speed of customs clearance. The UNJLC assists with real-time tracking of all UNICEF containers. In serious emergencies relief aid is air-lifted to the region of crisis. Generally UNICEF relies on trucks to get relief from the ports and warehouses to the affected regions in Zimbabwe (WFP, 2008). Partnership with UNJLC allows UNICEF to 
coordinate its services and requirements with other humanitarian and non-humanitarian agencies in Zimbabwe (UNJLC, 2008). The partners UNICEF shares resources with include WFP (WFP, 2008) and DHL in the corporate sector (DHL, 2006). It has also worked closely with the government, local authorities, the Zimbabwean military, and civil and commercial organisations in the countries it will be operating in. There is very close collaboration with the Ministry of Health and Child Welfare in Zimbabwe. It uses the ministry's personnel and facilities such as clinics and hospitals during immunisation programmes. There is also very close collaboration with the Ministry of Education, Sports and Culture in setting up and running children feeding schemes. UNICEF rents storage space (warehouses) and hires local contractors to transport aid to the different regions of the country. During Cyclone Eline, UNICEF worked with the Zimbabwe Civil Protection Unit and the Air Force of Zimbabwe to bring aid to those affected by the flooding. (UNICEF Zimbabwe, 2003).

\section{Problems and challenges faced by UNICEF in Zimbabwe}

The challenges faced in Zimbabwe include the geographical barriers with donor countries; archaic political and legislative practices adopted in the country; dilapidated infrastructure; and different cultural norms (UNICEFZimbabwe, 2003). There are problems with coordinating and synchronising the activities with all its different partners and sister organisations in a cost-effective manner to fulfil its mandate, especially given the fact that humanitarian emergencies can be random. One of the main problems has been the politicisation of all operations in the country by the Zimbabwean government.

\section{HUMANITARIAN LOGISTICS AT THE ZIMBABWE CIVIL PROTECTION ORGANISATION}

Many countries have set up protection organisations that focus on response preparedness, coordination of different humanitarian organisations and assistance in disaster recovery. The Zimbabwe Civil Protection Organisation (ZCPO) is an example.

\section{General Zimbabwe Civil Protection Organisation operations}

The ZCPO is a humanitarian disaster-response entity, which at its inception was coordinated by the Minister of Local Government Public Works and Urban Development and empowered by the Civil Protection Act Chapter 10.06 (1989). It is national policy for Civil Protection that every citizen of Zimbabwe should assist where possible to avert or limit the effect of humanitarian disaster. Central government initiates hazard-reduction measures through relevant sector ministries, with the local administration taking responsibility for implementing and maintaining effectiveness (Civil Protection Act, 1989). The system uses the existing government and private and NGO structures, whose regular activities normally contain elements of prevention and community development. These organisations are adopted structurally, materially and technically so that they can speedily shift from their regular 
activities to undertake protective, relief and rehabilitation measures in times of humanitarian disasters, without drifting too far from their operational principles and missions.

The ZCPO reacts according to the nature of the emergency. As an initial step, an assessment of the needs of the people caught up in a disaster is made. For instance, if there are floods in a rural area, the immediate needs of the people will be shelter and sanitation. It will be difficult to cater for the needs since people would be scattered all over the affected area. To make things easier in flood-prone areas, as a part of emergency preparedness response training, people are advised to gather at a designated central point, like a school or a clinic. Even then it may be difficult to reach affected people in the event of floods, as roads and bridges could be washed away. In such instances, the ZCPO liaises with the Zimbabwe National Army for helicopters to extract marooned people. In instances when it may not be necessary to rescue people but food and water is needed, the Air Force of Zimbabwe uses small planes and helicopters to drop food packs, water and any other necessities such as plastic sheeting or tents for temporary shelter. Trucks from the government's Central Mechanical Equipment Department may also be mobilised.

For example, during Cyclone Eline, a flooding disaster occurred in February 2000 and many areas were ravaged. There were many fatalities and there was need for body bags, shelter, food and water, and the ZCPO had to react quickly to reduce stress and deaths. In such extreme cases the ZCPO has the legislative power to commandeer private transport. However, most benefits are realised when such disasters occur if pre-arrangements for the disaster have been made through emergency preparedness. In every rural community a record is kept of everyone who has potentially useful equipment, like a tractor, a lorry or buildings. By prior arrangements with the owner, such equipment is mobilised in the event of disasters. Local companies, mainly mines, also assist by providing their vehicles for use and by giving needed materials when humanitarian disasters occur.

\section{Problems and challenges faced by the ZCPO}

In cases when a humanitarian emergency occurs in remote areas, serious communication problems can occur. In some cases the affected areas do not have any communications infrastructure in place. At times only one-way radio communication is available. Other areas, for instance Chicualacuala in the southern parts of Zimbabwe, cannot receive early warnings because they only receive foreign radio transmissions. In other areas like Muzarabani, VHF radios are available at local police stations. The efficiency of humanitarian logistics operations can be limited by the shortage of personnel as well as lack of electricity. The ZCPO is also not well funded and relies heavily on donor funding for its programmes. This is a problem given the current donor fatigue and targeted sanctions facing Zimbabwe. In cases of disaster the ZCPO initially appeals locally for aid and individuals and the business 
community can respond to a central point. When local help is inadequate, an appeal is launched, regionally, nationally and even internationally in very extreme and unmanageable cases. One main challenge is a lack of accountability by the bureaucrats and politicians managing these operations. Cases of misuse of donations have been experienced and these have tended to dampen local response to appeals for assistance.

It was noted that the ZCPO falls short in many respects based on humanitarian logistics performance indicators. It faces many challenges financially, materially and structurally. In terms of the structures in place it is the director and deputy director who can authorise the release of funds to secure the materials and equipment needed. This is too bureaucratic. Although both these individuals are on standby 24 hours a day during an emergency, it still does not satisfy the issue of expediency. The other aspect relates to the fact that the ZCPO does not own logistics equipment. Problems might arise between the different government ministries, departments and arms when there are clashes of interests. For example the ZCPO might need to use some vehicles urgently, but the army might feel they are not obliged to act with the necessary speed without authorisation by the army commanders, critically delaying response to disasters.

\section{ANALYSIS AND DISCUSSION}

The overarching problems and challenges facing all the humanitarian organisations logistics systems in Zimbabwe are mainly to do with the poor political and economic situation prevailing in the country. This has resulted in disengagement by the donors, weaker currency, reduced local capacity, absence of the rule of law, inappropriate local and central government interference, customs delays and political violence. It has also contributed to poor infrastructure like bad roads, lack of bridges, and inadequate information and communication technologies. It has resulted in chaos in society, facilitating the spread of HIV/AIDS, rapidly increasing the number of beneficiaries and creating a donor-dependency syndrome, thus increasing demand for humanitarian assistance beyond planned capacities. This is against a background of brain drain as qualified, skilled, educated and trained personnel left the country. Increasingly, the Government of Zimbabwe has abdicated its responsibilities and pays only lukewarm attention to humanitarian needs, operations and logistics. Misuse, misallocation, theft, leakages, corruption and prohibitive bureaucracy have become rife due to government involvement. Conflicts of ministries have also impacted assistance delivery. These problems and challenges were identified in all five organisations studied. Humanitarian organisations have to find ways of dealing with them through a united front until the political and economic situation stabilises. Issues of political violence, disrespect of the conduct of war, and terrorism has affected many humanitarian logistics operations (Miskel, 2000; Lautze et al., 2004). This area needs attention and the provision of security for humanitarian operations is increasingly important. 
Specific problems and challenges also existed in each organisation. The main issues at WFP were to do with delays due to certification or processing of genetically modified food, location and relocation of food storage hubs, mismatch of donations and needs, challenges of supply chain collaboration with partners, and lack of logistics education and skills. ZRCS has scarce resources and high staff turnover, and is failing to cope with the high demand for its services. At the $\mathrm{WHO}$, the main issues were to do with poor coordination, excessive demand for services and access to primary health care, drug abuse by youths and inequitable access to medicines. At UNICEF, the disconnection between donors, suppliers and recipients, differences in cultural norms and coordination problems with partners and sister organisations were noted. Supply chain coordination problems are a common feature in humanitarian logistics (Balcik et al., 2010). ZCPO operations are affected by lack of Zimbabwean radio reception in some parts of the country, weakening early warning and information dissemination capability. It has inadequate equipment and resources, suffers from donor fatigue, is highly bureaucratic and has to contend with internal conflict and supply chain coordination problems associated with its very large stakeholder and partnership base.

\section{SUGGESTED SOLUTIONS, RECOMMENDATIONS AND CONCLUSION}

\section{Suggested solutions for WFP}

It was discovered that most of the people employed as logisticians at the WFP Zimbabwe were not formally trained in humanitarian logistics. Competency-based capacity-building initiatives and mechanisms need to be developed and supported so that humanitarian logisticians' skills and know-how are raised to professional levels, and supported by appropriate training discipline, accreditation and continuous professional development to meet the evolving systems and challenges. New employees could be sourced from humanitarian logistics schools and corporate environments to capitalise on core professional skills and experiences, and mentoring as well as continuous professional development and coaching could be instituted.

Copying and improving and collaborating with the corporate world and the military are recommended to improve efficiency and effectiveness. The WFP can catch up rapidly through collaboration with business corporations willing to share know-how, systems and resources to improve logistics operations. Coalitions can improve expertise and knowledge in radio, satellite, licensing and hardware. The existing loose and informal operations need to be reorganised so that they are tighter and accountable in order to minimise loss of commodities and maximise effectiveness. The WFP in Zimbabwe could work closer with World Vision, for example, to benefit from its humanitarian logistics network. World Vision is a Christian relief, development and advocacy organisation that is $80 \%$ funded from private sources (individuals, foundations and corporations). The rest is funded by governments and multilateral agencies. The organisation is dedicated to working with children (child support 
is $50 \%$ of the funding), families and communities to overcome poverty and injustice. It has pre-positioning units in three places: Denver, US (primary focus serving the Americas); Brindisi, Italy (primary focus Middle East, Central Asia and Africa); and Hanover, Germany (a smaller unit serving diverse logistical needs). These can deliver supplies worldwide within 72 hours if necessary and can help in case of emergencies in Zimbabwe. WFP membership of the Humanitarian Logistics Council (HLC, 2002) can be considered to heighten the visibility of the sector and stimulate improved logistics management. The Council brings together key logistics managers in the humanitarian sector with the aim of encouraging collaboration, integration, standardisation, synergy and joint product development.

\section{Suggested solutions for the Zimbabwe Red Cross Society}

The ZRCS needs to create more assistance lines by having updated appeals to the regional and international federations of Red Cross societies to better match existing demand. There might be a need to focus on either HIV/AIDS prevention or mitigation (antiretroviral distribution) to optimise resource use. Cheap water purification systems and centralised potable water supplies could improve service delivery. The organisation needs to reduce staffing levels and improve salaries and conditions of service to retain a leaner, but more effective staff complement. It also needs to re-affirm international protocols and push for sister organisations and the IFRC to engage the Zimbabwean government to avoid violence against its staff.

\section{Suggested solutions for the WHO in Zimbabwe}

The following are suggested to reduce WHO logistics challenges in Zimbabwe: Ensure hospital service quality improves in many affected areas; rehabilitate critical hospitals especially referral centres in the main cities; encourage partnerships with governments, NGOs and the private sector in health assurance and delivery; maintain health experts and surveillance on epidemics; provide an adequate back-bone of medical supplies and logistics; agree on priorities between parties and establish coordination and joint action.

\section{Suggested solutions for UNICEF Zimbabwe}

UNICEF has tried to reduce the risk of these challenges by forming effective partnerships, by the presence of its employees on the ground and through nurturing good relations with governments, local authorities, NGOs and other civil organisations in the country.

\section{Suggested solutions for the ZCPO}

The management systems of the ZCPO need to be improved to reduce or eliminate any leakages through theft and corruption. There is also a need to decentralise authority and put in place effective humanitarian logistics management systems to avoid corruption, ineffectiveness and inefficiency. It might be necessary for the ZCPO to have their own small fleet of vehicles and then get extra help later when the most critical decisions and 
implementation steps have been taken. There is also need for the ZCPO to establish branches in the major towns of the country to raise awareness on disaster preparedness in more people.

\section{General recommendations}

Based on the study, the following collaboration areas and issues are proposed:

- An education, teaching, training and research network is proposed that can initiate and/ or consolidate educational programmes in humanitarian logistics in the country, leading to a variety of competencies and qualifications.

- Development of a humanitarian logistics network that brings together participants from industry, government and academia to develop specialised systems for humanitarian logistics is required. The focus can be on technology and system adaptation from business and military logistics systems; development of systems that respond flexibly to changing needs; and identification of opportunities for exploiting synergies.

- Typical topic areas that can be considered for system development and improvement are on: defining the role of humanitarian organisations in infrastructure development and maintenance; minimising the impacts of politics, security and war on operations; location decisions for main, sub-, and small warehouses and storage areas for cost optimisation and higher impact factor; quick methods to develop distribution networks for identified operations; own and lease decisions for logistics equipment and infrastructure given the limited term of operations; managing the mismatch between donations and demands/ needs; formalising the delivery end-points; information and communication technologies for humanitarian logistics; rapid catch-up models for systems to match corporate, global and military logistics systems; developing peer networks for different humanitarian organisations; the role of volunteers in humanitarian logistics $(H L)$; development, impact and effectiveness of $\mathrm{HL}$ emergency preparedness and response systems in disasterprone areas; response systems to rapidly increasing relief demand or high demand emergency situations; routing problems for $\mathrm{HL}$; managing the military-civil interface in $\mathrm{HL}$ for effective coordination during disasters; and legal issues in HL.

\section{Conclusion}

This paper has presented mini-case studies for humanitarian logistics operations in a number of organisations that operate in Zimbabwe. The above recommendations contribute to further discussion and dialogue on the development of collaborative networks that can assist in attending to the challenges that are faced by humanitarian organisations' logistics operations. Lessons from the Zimbabwean experience can be extended to assist in informing decision-making in humanitarian logistics in other African countries and worldwide. One outcome could be a communication unit to serve the wider humanitarian community during a large-scale disaster. 


\section{REFERENCES}

Balcik B., Beamon B. M., Krejci C. C., Muramatsu K. M. \& Ramirez M. 2010. Coordination in humanitarian relief chains: Practices, challenges and opportunities, International Journal of Production Economics, 126: 22-34.

Caplice, C. \& Sheffi, Y. 1994. A review and evaluation of logistics metrics. The International Journal of Logistics Management, 5(2): 11-28.

Civil Protection Act, 1989, The Civil Protection Act of Zimbabwe - Policy and disasters management Organisation in Zimbabwe.

DHL. 2006. Deutsche Post World Net and UNICEF engage in a strategic partnership to reduce child mortality. http://www.dhl.com/publish/g0/en/press/release/2006/130906. high.htmlundefined (accessed 17 February 2010).

Dumond, J. 2000. Define-Measure-Improve: The change methodology that has propelled the army's successful velocity management initiative. http://www.rand.org/publications/RB/ RB3020/index.html (accessed 30 November 2009).

Gustavsson, L. 2006. Humanitarian logistics: Context and challenges emergency response and disaster mitigation. World Vision International.

Gyongyi, K. \& Tatham, P. 2009. Humanitarian logistics performance in the light of gender. International Journal of Productivity and Performance Management, 58(2): 174-87.

HLC, 2002, Humanitarian Logistics Council. Established in 2002 by the Fritz Institute.

IFRC. 2002. Appeal 2002, April Report. International Federation of Red Cross and Red Crescent Societies Journal.

IFRC. 2007. http://www.ifrc.org/docs/appeals/annual/06/MAAZW00101.pdf (accessed on 15 February 2010).

IFRC. 2010. International Federation of the Red Cross and Red Crescent Societies. http:// www.ifrc.org (accessed on 1st September 2010).

Lambert, D. 2001. Supply chain metrics. The International Journal of Logistics Management, 12(1): 1-20. 
Lautze, S., Leaning, J., Raven-Roberts, A., Kent R. \& Mazurana D. 2004. Assistance, protection, and governance networks in complex emergencies, The Lancet, December 11, 364: 2134-41.

Mazvimavi, D. 2000. Baseline studies for an integrated rural development programme in Matobo District, Zimbabwe. German Red Cross \& Zimbabwe Red Cross, Harare. pp. 44.

Meyer, M. 2005. Can performance studies create actionable knowledge if we can't measure the performance of the firm? Journal of Management Inquiry, 14(3): 287- 91.

Miskel, J. F. 2000. Better tools for humanitarian missions. Orbis, Spring, pp 295-305.

Oloruntoba, R. 2010. An analysis of the Cyclone Larry emergency relief chain: Some key success factors. International Journal of Production Economics, 126: 85-101.

Thevenaz, C. \& Resodihardjo, S. L. 2010. All the best laid plans ... conditions impeding proper emergency response. International Journal of Production Economics, 126: 7-21.

UNICEF Zimbabwe. 2003. Situational assessment and analysis of children in Zimbabwe. UNICEF, Harare.

UNICEF. 2008. UNICEF http://www.unicef.org (accessed 15 January 2010).

UNJLC. 2008. United Nations Joint Logistics Centre, http://www.unjlc.org/about/ (accessed 2 February 2010).

WFP. 1986. Food aid and work. WFP Publication.

WFP. 1994. Annual Report: Linking relief and development. WFP Publication.

WFP. 1995. Annual Report: Ending the inheritance of hunger. WFP Publication.

WFP. 2005. Annual Report. WFP Publication.

WFP. 2008. World Food Programme Logistics, http://www.wfp.org/operations/logistics and http://www.wfp.org/operations/logistics/w_sea.asp?section=5\&sub_section=2 (accessed 30 October 2009).

WFP in Africa. 1984. Fighting famine and assisting development. WFP Publication. 
WFP Zimbabwe. 2006. Food aid and work. WFP Publication.

WHO. 2010. World Health Organisation, http://www.who.int/en/ (accessed 2 September 2010).

Table of acronyms and abbreviations

\begin{tabular}{|l|l|}
\hline UNJLC & United Nations Joint Logistics Centre \\
\hline WFP & World Food Programme \\
\hline NGO & non-governmental organisation \\
\hline GM & genetically modified \\
\hline FIFO & first in first out \\
\hline FEFO & first to expire first out \\
\hline IT & information technology \\
\hline MIS & management information system \\
\hline IFRC & International Federation of the Red Cross and Red Crescent Societies \\
\hline ZRCS & Zimbabwe Red Cross Society \\
\hline ICRC & International Community of the Red Crescent Society \\
\hline NEC & National Executive Council \\
\hline ARV & anti-retrovirals \\
\hline WHO & World Health Organisation \\
\hline UNICEF & United Nations Children's Fund \\
\hline UN & United Nations \\
\hline ZCPO & Zimbabwe Civil Protection Organisation \\
\hline HLC & Humanitarian Logistics Council \\
\hline HL & Humanitarian Logistics \\
\hline
\end{tabular}

